Published in final edited form as:

Hepatology. 2016 February ; 63(2): 674-675. doi:10.1002/hep.27846.

\title{
Reply to the comments on HEP-14-1354.R2
}

\author{
Dechun Feng, PhD, Mingjiang Xu, MD., PhD, and Bin Gao, MD PhD \\ Laboratory of Liver Diseases, National Institute on Alcohol Abuse and Alcoholism, National \\ Institutes of Health, Bethesda, MD 20892
}

We greatly appreciate the comments raised by Gineste et al. As we mentioned in our paper, ${ }^{1}$ we examined Klebsiella pneumonia $(\mathrm{Kp})$ infection in $\mathrm{II}_{-} 6^{-/-}$mice when we was exploring the possible mechanisms underlying liver LCN2 regulation. We measured serum LCN2 levels after Kp challenge. In agreement with the results from Gineste et al., we obtained comparable serum LCN2 levels in WT and $I I-6^{-/-}$mice 12 and 24 hours post Kp injection. However, $\mathrm{II}-6^{-/-}$mice became very ill and moribund 12 hours post Kp challenge, suggesting $I I-6^{-I-}$ mice are more susceptible to bacterial infection. These findings are consistent with several previous reports. ${ }^{2-4}$

We can't simply exclude the role of IL-6/IL-6R/STAT3 signaling in regulating liver LCN2 production based on the data from $I I-6^{-/}$mice because $I I-6^{-1-}$ mice have much higher bacterial titers and much higher levels of other cytokines in the serum (eg. IL-6 family cytokines, IL-1) than wild-type mice post infection, and these cytokines can compensate to induce LCN2 production in hepatocytes. In addition, Gineste et al. used very high doses of LPS (1000ng/g body weight) and E coli, which upregulated liver $L c n 2$ mRNA by more than 1000-fold; while in our studies, a lower dose of bacterial was used, and hepatic expression of Lcn2 mRNA was upregulated by less than 50 -fold. ${ }^{1}$ Thus, it is likely that compensatory elevation of other mediators promotes hepatic $L \mathrm{cn} 2 \mathrm{mRNA}$ upregulation in $\mathrm{II}-6^{-/-}$mice.

In our paper, we used hepatocyte-specific IL-6 receptor knockout mice (IL-6 $\mathrm{R}^{\mathrm{Hep}-/-}$ ) in which IL-6/IL-6R signaling was only disrupted in hepatocytes while the effects of IL-6 on other cell types especially immune cells are intact. We believe that IL-6 $\mathrm{R}^{\mathrm{Hep}-{ }_{-}-\text {mice are }}$ more suitable for studying the regulation of LCN2 in the liver by IL- 6 . We observed lower LCN2 levels in IL-6 $\mathrm{R}^{\mathrm{Hep}-/-}$ mice 8 and 24 hours after bacterial challenge than those in wildtype mice; however, similar levels of serum LCN2 levels were observed in IL-6 $\mathrm{R}^{\mathrm{Hep}-/-}$ and wild-type mice 36 hours after Kp challenge. This suggests that IL-6 plays an important role in inducing LCN2 production in hepatocytes at early stage of bacterial infection and other cytokines (eg. IL-6 family cytokines and IL-1) may compensate to induce the production of LCN2 in the absence of liver IL-6/IL-6R signaling pathway at later stage of host defense.

\section{References}

1. Xu MJ, Feng D, Wu H, et al. Liver is the major source of elevated serum lipocalin-2 levels after bacterial infection or partial hepatectomy: a critical role for IL-6/STAT3. Hepatology. 2015; 61:692-702. [PubMed: 25234944]

2. Kopf M, Baumann H, Freer G, et al. Impaired immune and acute-phase responses in interleukin-6deficient mice. Nature. 1994; 368:339-42. [PubMed: 8127368] 
3. Dalrymple SA, Lucian LA, Slattery R, et al. Interleukin-6-deficient mice are highly susceptible to Listeria monocytogenes infection: correlation with inefficient neutrophilia. Infect Immun. 1995; 63:2262-8. [PubMed: 7768607]

4. van Enckevort FH, Sweep CG, Span PN, et al. Reduced adrenal response and increased mortality after systemic Klebsiella pneumoniae infection in interleukin-6-deficient mice. Eur Cytokine Netw. 2001; 12:581-6. [PubMed: 11781184] 